Marshali, C. R. \& Walkiey, V. T. (1952). J. gen. Microbiol. 6, 374-376.

\title{
The Homofermentative Lactobacilli of Apple Juice
}

\author{
BY C. R. MARSHALL AND V. T. WALKLEY \\ Seager, Evans and Co. Ltd., 14 Deptford Bridge, London, S.E. 8
}

SUMMARY:Three species of homofermentative lactobacilli, identified as Lactobacillus delbrueckii, L. plantarum and L. leichmannii have been found to be of widespread occurrence on apples and in the expressed juice. Precautions must be taken to arrest their development during the processing of apples intended for the production of unfermented apple juice, otherwise the juice will be rendered unpalatable through development of excess acidity.

Some of the bacterial disorders of cider described by Warcollier (1928), such as Graisse disease and mannite disease, are caused by lactobacilli of the heterofermentative type which produce not only lactic acid but also acetic acid, alcohols and carbon dioxide from carbohydrates. An excellent account of the occurrence and development of these organisms in cider has been published by Steuart (1949).

Homofermentative lactobacilli producing mainly lactic acid and only traces of by-products from carbohydrates are also present in apple juice. They occur in large numbers on apples and we have observed considerable fluctuations in their population during growth and maturity of the fruit on the tree. Freshly expressed juice from sound fruit always contains a small number of these bacteria, but when the fruit contains a large proportion of rot their incidence in the juice increases. For the production of pure natural apple juice, the juice is always fined and filtered prior to bulk storage in refrigerated pressure tanks, and this treatment decreases the complement of organisms in the juice. No multiplication occurs during bulk storage of carbonated juice at a temperature of $37^{\circ}$, in fact, the organisms tend to diminish with prolongation of the storage period. Since no account of the presence of homofermentative lactobacilli in apple juice appears to have been published we describe in this paper three organisms of this group which we have encountered on fruit and in the juice during the production of pure natural apple juice at a fruit juice factory in Gloucestershire.

\section{METHODS}

Bergey's Manual (1948) describes eleven well defined species of homofermentative lactobacilli, and divides them into two subgenera based upon their optimum growth temperatures. We have used this key for identifying our isolates. As a group, these organisms occur as long, slender rods; they are Gram-positive, catalase negative, micro-aerophilic, non-spore forming, and convert carbohydrates into lactic acid with small amounts of by-products.

We used Blickfeldt's solution agar for isolation and both this medium and apple-juice agar for observation of morphological and colony characteristics. Blickfeldt's solution and apple juice were used for examination of growth in 
liquid media. Biochemical reactions were carried out on $2 \%(w / v)$ solutions of the appropriate substrate in yeast water.

\section{ORGANISMS ISOLATED}

Many cultures of homofermentative lactobacilli were encountered and were eventually sorted into three distinct types. These were allotted culture numbers and are described below.

Culture $R$. 31. Isolated from fresh juice and from apples used for the production of juice, was present on sound fruit and also on fruit infected with Blue Mould (Penicillium expansum) and with Brown Rot(Sclerotiniafructigena), thus indicating a wide distribution. It was also encountered in tank-stored juice but rapidly diminished during storage. On nutrient agar at 25 and $30^{\circ}$ it appeared as non-sporing, non-motile, single rods 6-7 $7 \times 1 \mu$., and also in short chains. The rods were Gram-positive and catalase negative. After 7-14 days some curved forms were observed. On apple-juice agar, colonies appeared in 2 days, attaining a diameter of $2 \mathrm{~mm}$. after 3 days. Colonies were refractile, mucoid, slimy and moist, with edges entire, round, and raised centre. In liquid media a uniform turbidity was produced at 25 and at $30^{\circ}$; after 4 days, a deposit was produced, with very little surface growth, and the organism appeared to be a faculative anaerobe. Optimum growth developed within the range $40-45^{\circ}$. Lactic acid was produced from glucose, dextrin, sucrose and maltose, but not from lactose.

These characters correspond to those of Lactobacillus delbrueckii(Leichmann) Beijerinck.

Culture $W .19$. This organism was present on apples and in the expressed juice at all stages of processing, but rapidly decreased during bulk storage. On apple-juice agar, it appeared as a short $\operatorname{rod} 2 \times 0 \cdot 5-1 \mu$. with a tendency to barrel and coccoid form. It was Gram-positive, catalase negative, non-spore forming, and non-motile. Colonies appeared very similar to those of Culture R. 31. In liquid media a slight surface growth appeared in 8 days, assuming the form of an extremely thin surface film, which when disturbed, broke into small fragments and sank. Growth in apple juice was slow with very little surface growth, a faint turbidity appearing after 4 days accompanied by a slight deposit. The organism was microaerophilic with an optimum temperature of $30-37^{\circ}$ and produced lactic acid from lactose, sucrose, maltose, glucose and mannose.

Its identity was established as L. plantarum (Orla-Jensen) Holland.

Culture $\boldsymbol{R}$. 34. This was encountered on apples and in the juice at all stages of processing. On apple-juice agar, it occurred as short slightly curved rods $\mathbf{1 . 5} \times \mathbf{0 . 5} \mu$. In old cultures there was a tendency towards a coccoid appearance with slight chain formation. The rods were Gram-positive, catalase negative, non-motile and did not produce spores. Colony appearance was similar to that of the two previous species. The organism was microaerophilic with optimum growth at $30^{\circ}$ and in liquid media formed a deposit and only a slight film after 7 days. Acid was produced from lactose.

The above characteristics established its identity as L. leichmannii Bergey et al. 


\section{DISCUSSION}

L. plantarum and L. leichmannii are found widely distributed in nature in fermenting plant and animal products, and $L$. delbrueckii is invariably found in fermenting vegetable and grain mashes.

We have found all three organisms to be of frequent occurrence in apple juice, and although they are less harmful there than organisms of the heterofermentative group it is desirable that adequate precautions be taken to arrest their development before they produce excess acidity and render the juice unpalatable. Fortunately their growth is retarded in juice which is carbonated and stored in bulk at low temperatures. Their inactivation in juice pasteurized in bottle has been made the subject of a separate study.

We wish to thank the Directors of Seager, Evans and Co., for permission to publish this paper.

\section{REFERENCES}

Bergey's Manual of Determinative Bacteriology (1948). 6th ed. edited by Breed, R. S., Murray, E. G. D. \& Hitchens, A. P., p. 350. London: Baillière, Tindall and Cox. Steuart, D. W. (1949). The role of the heterofermentative lactobacilli in cider making. J. Soc. chem. Ind., Lond. 68, 250.

Warcollier, G. (1928). Cidrerie, 3rd ed., p. 377. Paris: Baillière et Fils.

(Received 8 December 1951) 